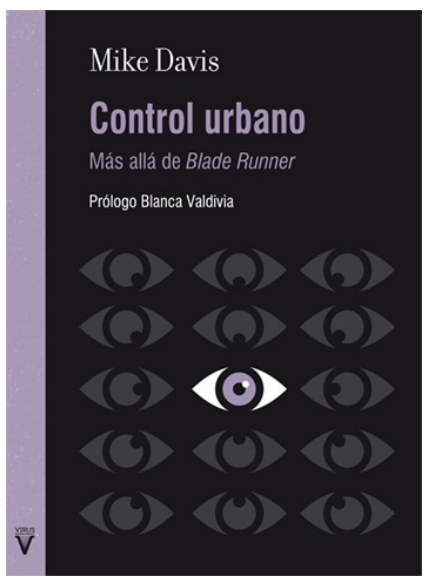

El ántropo no debe confiar más en las oposiciones de lo irreflexivo $y$ lo reflexivo, de lo inconsciente y lo consciente, de lo espontáneo y lo mecánico (...) que no cuente tampoco con la oposición espiritu

- materia, imaginándose que

representa el espiritu porque se sirve de armas espirituales. Al contrario: debe ser materialista más y mejor que el ciberántropo (...). Ya sabe que siempre será vencido en el plano de la lógica, de la perfección

técnica, del rigor formal, de las funciones y las estructuras (...). Vencerá por el Estilo Henri Lefebvre (1967/1971), p. 182.

\section{“HE VISTO COSAS QUE USTEDES NO CREERÍAN" \\ BLADE RUNNER SEGÚN MIKE DAVIS}

Horacio Espinosa. Observatorio de Antropología del Conflicto Urbano (OACU), Barcelona, España.

Título libro: Control Urbano. Más allá de "Blade Runner" Autor: Mike Davis Edición: Virus editorial, 2020 (160 pp.) ISBN: 978-84-I7870-04-I

Los Ángeles, año 1992. Las llamas danzaban aún con vivaz ferocidad en la larga noche ardiente que duraría una semana y que arrasaría con todo. Sesenta y tres muertos, más de dos mil heridos. El detonante habría sido la detención y tortura policiaca al taxista negro Rodney King, pero las causas profundas de la rabia "se pierden en el tiempo, como lágrimas en la lluvia”. La detención, los gritos, las espontáneas manifestaciones, los disturbios, los espectaculares saqueos y el fuego eran escupidos en directo por aparatos de TV aún ochenteros de imagen granulosa. La ciudad de Los Ángeles ardiendo globalmente en la pantalla. Cada conflicto de los años noventa fue globalizado gracias a la televisión: la primera guerra del Golfo, la guerra de Yugoslavia... en la primera el 
fuego provocaba miedo; en la segunda, tristeza. Pero ver Los Ángeles arder era distinto, era excitante. La espectacularización televisiva de los conflictos daría pie a que Baudrillard (1991) afirmase que "la guerra del Golfo no había tenido lugar". La guerra se encontraba en cualquier sitio con Tv. En la misma red sináptica donde almaceno las imágenes de estos conflictos hay una canción como banda sonora; empieza con el ulular de una voz negra que simula una sirena de policía, le sigue un beat insidioso y Krs-One rapeando sobre el conjunto: that's the sound of da Police, that's the sound of da Beast...

En el libro Control urbano. Más allá de "Blade Runner" (2020), la editorial Virus de Barcelona reúne cuatro ensayos clásicos de Mike Davis escritos entre 1992 y 1995 . El artículo principal es, sin duda, el mítico "La ecología del miedo. Más allá de Blade Runner", donde Davis analiza el caso de Los Ángeles, comparando esta ciudad con las distopías urbanas presentes en la literatura y cine cyberpunk, sobre todo en la película Blade Runner de 1982, adaptación de ¿Sueñan los androides con ovejas eléctricas? (1968) de Phillip K. Dick. Solo uno de los ensayos incluidos no trata sobre Los Ángeles, sino sobre Las Vegas. Este no desentona en absoluto, ya que la ciudad de los casinos, al igual que Los Ángeles, ha crecido a partir de un modelo urbano basado en la segregación, tanto de clase como racial. Cada uno de estos trabajos forma parte del arsenal epistémico de las izquierdas. Sus títulos gritan con elocuencia su contenido: "Los Estados Unidos urbanos contemplan su futuro. En Los Ángeles arden todas las ilusiones", "El caldero racial", "Un campo de fábricas del infierno"...
A través de estos ensayos, Davis "invierte" los argumentos de clásicos de la Escuela de Chicago como The City (1925/1992), donde se habla de las ciudades en términos de "ecología humana", con una clara tendencia a favorecer interpretaciones homeostáticas antes que conflictivistas. Davis, por el contrario, habla de una "Ecología del Miedo". Las elites urbanas no temen desestabilizar el sistema urbano si esto les confiere ganancias. Bailan con las desigualdades hasta el punto de tolerar su propia bunquerización. Alimentan el miedo a las clases trabajadoras pagando el precio de ver crecer el odio a los ricos. Sin embargo, a pesar de su presentación "invertida", el esquema de Davis sigue siendo "ecológico". Manuel Castells (1972/2014, pp. 142-145) realiza una dura crítica a la ecología humana de la Escuela de Chicago y su excesivo "análisis espacial", que ignora "las leyes estructurales de la producción". Esta misma crítica podría hacérsele a Mike Davis, pero incluso con esto, no minaría ni un ápice la relevancia de estos trabajos.

La demonización de los barrios pobres de mayoría negra y/o latina está en la base de la creación y posterior mediatización de estereotipos como que los pobres son proxenetas, drogadictos, criminales o infanticidas, por lo que resulta vital crear "zonas protegidas" y "patrullas vecinales" que mantengan a los barrios pobres en constante vigilancia y acoso (Davis, pp. 48-64). Según Davis, Blade Runner es el único escenario posible para una ciudad que, ante el reto de reducir las desigualdades, no opta por la inversión ingente en programas sociales y de reforma urbana, y prefiere, por el contrario, los recortes, el ahorro público y la privatización. Y es que a las clases medias les puede más su 
aversión a "la fiscalidad progresiva" que su "obsesión por la seguridad personal y el aislamiento social" (Davis, p. 33). Cuando, en los ańos sesenta, un lobby de la elite angelina pronóstica que el centro histórico de Los Ángeles será "invadido” por los pobres, debido a la desinversión sistémica en la zona, el llamado Comité de los 25 consigue sacar adelante un plan radical: que las clases medias abandonen el centro, reducir la inversión pública al nivel de la caridad y promover la creación de un nuevo núcleo urbano para ricos, que sin disimular llamarían Bunker Hill (Davis, pp. 33-39).

En el corazón de la edificación de un nuevo núcleo urbano estaría una estrategia de doble segregación: aislar a los pobres de los ricos y viceversa. Por un lado, el Bunker Hill rompería sus conexiones con el antiguo centro construyendo "plataformas peatonales elevadas", sistemas de monitorización de los rascacielos, "reubicación de barreras arquitectónicas" y "edificación de pilares de hormigón y muros de autopista" (Davis, p. 35). Esto se vería complementado por la difusión de una nueva cultura yuppie, un nuevo estilo de vida, donde se entendía que era más rico quien tuviera mayor "capacidad de proveerse de ángeles de la guardia electrónicos que velen por ti” (Davis, p. 37). Un tercer y último elemento de segregación a la alta sería la proliferación de edificios inteligentes dotados de sistemas sensibles con capacidad para "ver, oler, detectar movimientos, cambios de temperatura o humedad"; Davis llegará a decir que, a partir de ahí, "la frontera entre arquitectura y mantenimiento del orden se difuminaría" (pp. 36-38). El Bunker Hill quedaría bunkerizado. Los Ángeles como un nuevo paradigma de la segregación radical gracias a su urbanismo securitario. Lo que Edward Soja $(2000 / 2008)$ posteriormente denominaría "modo postmetropolitano de regulación social y espacial” (p. 420).

Este urbanismo defensivo, en un sentido militar, sería exitoso en los objetivos que se había planteado, y así, durante los disturbios por el caso de Rodney King, el núcleo urbano empresarial saldría indemne:

$$
\begin{aligned}
& \text { Pulsando unos cuantos botones en } \\
& \text { sus cuadros de mando, los guardias } \\
& \text { de seguridad de los grandes edifi- } \\
& \text { cios bancarios pudieron bloquear } \\
& \text { todos los accesos a sus costosos in- } \\
& \text { muebles. Puertas de acero a prue- } \\
& \text { ba de balas se deslizaron sobre las } \\
& \text { entradas, las escaleras mecánicas se } \\
& \text { detuvieron al instante y las verjas } \\
& \text { electrónicas impidieron el acceso a } \\
& \text { las zonas peatonales. (Davis, p. 36) }
\end{aligned}
$$

Pero la autosegregación de los ricos sería incompleta sin la segregación forzada de los pobres. Aquí es donde entra en acción la creación de "los barrios de control social” (Davis, p. 48). Es decir, barrios de clase trabajadora donde el estado de excepción se ha convertido en la norma. El barrio de MacArthur Park conocido como "Little Central America", será descrito etnográficamente en el segundo ensayo del libro (pp. 87-109). Davis quiere encontrar las causas de la ira de los jóvenes latinos del MacArthur Park. Ellos no se unen a las demostraciones de indignados por el caso Rodney King, sino por la violencia que viven todos los días a manos de la policía. También salen a luchar por la crónica segregación de sus comunidades.

A partir de "la guerra contra las drogas" declarada por Ronald Reagan en los ochenta, continuada por George Bush padre $y$, de hecho, brutalmente 
incrementada por el demócrata Clinton en los noventa, los barrios pobres norteamericanos estarían bajo el asedio continuo de la policía. La paranoia por el uso de crack haría de los barrios de clase trabajadora zonas de guerra. Barrios herméticos, vigilados y reprimidos. Franjas de Gaza en el centro de una de las capitales de la economía global. La introducción de cocaína por narcotraficantes centroamericanos formaba parte de una estrategia secreta del gobierno estadounidense para financiar a los grupos paramilitares anticomunistas en Nicaragua -"la contra"-. Era tal la sobreoferta de droga introducida en secreto por la CIA, que esta se abarataría y su excedente llegaría a los barrios pobres en su modalidad más adictiva: el crack.

Aunada a la militarización de los barrios, la locura por el crack vino acompañada de las leyes más absurdas en la enfermiza carrera en contra de las drogas. La más fatídica y aún vigente es la ley conocida como three-strikes and you're out (Davis, p. 134), que condena a cadena perpetua a cualquier ciudadano tres veces infractor, por menores que sean las infracciones. Esta ley, producto de la paranoia antidrogas, afecta principalmente a los chavales negros $y$ latinos desempleados, que, sin nada que hacer, vagan por las calles. Si cometen tres robos van a la cárcel de por vida. Por supuesto, California es uno de los Estados donde la ley ha sido aplicada con mayor severidad. Una de las consecuencias fue que, en cuestión de una década, Estados Unidos alcanzaría una población carcelaria de 2,16 millones, la más alta del mundo. Pero el caso de California, analizado individualmente, sería aún más delirante: con la aprobación de la three-strikes law, la población carcelaria pasaría de 50.000 en 1980 a 150.000 en 1990. Si California fuera un país, por sí sola ocuparía el tercer lugar entre los países con mayor número de presos (Davis, p. 134).

Mike Davis dedica el ensayo "Un campo de fábricas del Infierno" a analizar el caso de Calipatria, más que una prisión, un modelo urbano distópico, que se retroalimenta de las innovaciones en control urbano de Los Ángeles; y viceversa, en Los Ángeles se aplican y afinan técnicas carcelarias, como la vigilancia panóptica. Con cerca de 4.000 detenidos, Calipatria es una prisión privada que en la práctica funciona como una miniciudadela. Una heterotopía urbana en el sentido dado por Foucault (1967/1984). Esta urbanización carcelaria de carácter privado se enfrenta al reto de mantener un negocio rentable, contratando la menor cantidad de vigilantes, sin que se le escapen los presos por esta razón.

Para conseguir este fin se desarrolla un sistema de "supresión total de la intimidad” (David, p. 139), se erige una enorme torre panóptica y se instala una valla electrificada de 5.000 voltios, es decir, 100 veces la cantidad de electricidad letal para un ser humano. Esta "valla de la muerte" (Davis, p. 137) se vuelve problemática cuando la Sociedad Protectora de Animales (SPA) denuncia a Calipatria por la cantidad de animales carbonizados que mueren en la desmedida valla. Se crea entonces un sistema de protección de la fauna, lleno de túneles, pasadizos y refugios, que llena de orgullo a las autoridades de la prisión; hablan de "la única valla de la muerte completamente ecológica” (p. 137), que garantiza asar a la parrilla solo a los humanos. Una valla de sensibilidad vegana. 
Mike Davis valoraba la obra revolucionaria de los escritores cyberpunk de la década de los ochenta. Sobre Neuromancer (1984), de William Gibson, decía que se trataba de "ciencia ficción extrapolativa", una "teoría social prefigurativa y (...) política de oposición anticipatoria frente al ciberfascismo oculto en el horizonte que se avecina" (Davis, p. 31). Acertó. Ese ciberfascismo ya está aquí, pero ni lo que Gibson ni Davis podrían llegar a imaginar es que todos participaríamos tan dócilmente de él. Para empezar, voluntariamente traemos con nosotros el más efectivo dispositivo de rastreo y control creado hasta la fecha: el móvil.

Jean-Pierre Garnier (2020) llama a esta generación "los smartianos" (juego de palabras con martiens, en francés, marcianos), los creyentes en la tecnoreligión de lo Smart. A diferencia del fascismo original, impuesto a sangre $y$ fuego, este "neo-totalitarismo, deshumanizado" no necesita de violencia explícita: "El putsch tecnológico, permanente e invisible, opera en nombre del progreso, de la conveniencia y, de ahora en adelante, de la transición ecológica. La inteligencia artificial salvará el planeta. Al esperar este milagro, ella permite, primero, la administración desmaterializada de la población y, luego, el desencarnamiento del poder" (Garnier, 2020). Pues sí, los smartianos llegaron ya, y todo apunta a que su baile no es el cha-cha-chá, sino el baile del control urbano a nivel planetario.

\section{Referencias bibliográficas}

Castells, M. (2014). La cuestión urbana. Siglo XXI (publicado originalmente en 1972).

Foucault, M. (1984). "Of other Spaces, Heterotopias". Traducido de "Des Espaces Autres". Architecture, Mouvement, Continuité, (5), 46-49. https://foucault.info/documents/ heterotopia/foucault.heteroTopia. en/ (Charla original de 1967)

Garnier, J.-P. (2020, dic. 31). "El virus de la coacción". Traducido por José Mansilla. Observatori d'Antropologia del Conflicte Urbà. https://observatoriconflicteurba. org/2020/12/31/el-virus-de-lacoaccion/

Lefebvre, H. (1971). Contra los tecnócratas. Granica Editores (publicado originalmente en 1967).

Park, R. E., Burgess, E. W. \& Mckenzie, R. D. (1992). The City. University of Chicago Press (publicado originalmente en 1925).

Soja, E. (2008). Postmetrópolis. Estudios críticos sobre las ciudades y las regiones. Traficantes de Sueńos (publicado originalmente en 2000). 